\title{
Los grados de la intertextualidad en Los sinsabores del verdadero policía de Roberto Bolaño: algunos planteamientos en torno a la ficción y el silencio literario
}

\author{
Jonathan Gutiérrez Hibler ${ }^{1}$
}

Resumen. La obra de Roberto Bolaño es sin duda un pretexto para conciliar la intertextualidad con la teoría de los mundos posibles debido a la ruptura taxonómica en los grados de la primera. A pesar de tratarse de una obra póstuma, Los sinsabores del verdadero policía no resulta ser una obra inacabada, en realidad ésta comienza una vez que el lector se desplaza a otros textos del autor y ahí es posible resaltar la riqueza de sus grados en la intertextualidad. Este comportamiento es típico del silencio narrativo, considerado como un juego de huellas en la orientación del texto: no sólo encontramos al narrador o los narradores como los ejes principales de la selección y filiación de la información narrativa, también la apropiación de otros textos es lo que crea una expansión textual en todos los géneros, específicamente en el narrativo. El objetivo de este trabajo consiste en plantear algunas interrogantes a la luz de momentos específicos de esta novela, principalmente los de notoria presencia intratextual, como es el caso del poema de Rimbaud leído por Amalfitano.

Palabras clave: intertextualidad; Roberto Bolaño; mundos posibles; silencio; ficción; biografías infames; intratextualidad; huella.

\section{[en] The degrees of intertextuality in Roberto Bolaño's true cop's work: some approaches to fiction and literary silence}

\begin{abstract}
The works of Roberto Bolaño are for sure a good excuse to conciliate the intertextuality with the theory of possible worlds: we can see clearly a taxonomic rupture between the degrees of the first one. Even if this novel is a posthumous work, Los sinsabores del verdadero policía does not become an unfinished thing, instead it starts once the reader moves from one text to another, therefore this is how we can stand out the wealth of the degrees in the intextuality. This behavior is typical of the narrative silence - a game of traces in the orientation of the text-. Not only the narrator(s) is the principal road of the selection and filiation of narrative information, also the appropriation of other texts creates a textual expansion in every genre, especially in narrative. In this academic essay we're going to question some aspects of intertextuality through some specific moments of this novel, especially in those where the intratextual presence is notorious, such as the example in which Amalfitano reads a poem by Rimbaud.
\end{abstract}

Keywords: intertextuality; Roberto Bolaño; possible worlds; fiction; silence; infamous biographies; trace.

Sumario. 1. Consideraciones previas. 2. Amalfitano y "El corazón robado" de Arthur Rimbaud. 3. Lugones, Kafka y los monos según Amalfitano. 4. La poesía moderna latinoamericana y el Tao Te

1 Tecnológico de Monterrey, México.

E-mail: jonathan_gtzh@hotmail.com 
King de Santa Teresa. 5. Architextualidad y reescritura: el intercambio de géneros. 6. Algunas imposturas intratextuales: observaciones finales.

Cómo citar: Gutiérrez Hibler, J. (2017) Los grados de la intertextualidad en Los sinsabores del verdadero policía de Roberto Bolaño: algunos planteamientos en torno a la fícción y el silencio literario, en Anales de Literatura Hispanoamericana 46, 463-477.

En enero de 2011 la editorial Anagrama publica Los sinsabores del verdadero policía, obra póstuma del escritor Roberto Bolaño, acompañada de un prólogo escrito por J. A. Masoliver Ródenas y una nota editorial por Carolina López. El primero resalta una singularidad de esta novela debido a la incorporación de antiguos personajes de otras obras de Bolaño, pero con notables variaciones ${ }^{2}$. Al tratarse Los sinsabores del verdadero policía de una obra singular en el universo de este escritor, se presenta ante nosotros una serie de reflexiones acerca de la ficción y, por supuesto, la intertextualidad. Por un lado tenemos las variaciones como un signo de distorsión y reescritura y, por el otro, la inconmensurabilidad de los mundos posibles en el plano de la contradicción, aunque no definitiva, sí sugerente debido a los ejemplos entre ésta y el resto los escritos de Bolaño.

El objetivo de este trabajo es plantear algunas preguntas sobre la intertextualidad en torno a la influencia de los mundos posibles. Ésta posee grados en su desarrollo a lo largo del texto, no funciona solamente en el ámbito de la cita explícita o implícita, sino que se observan nuevas problemáticas más allá de la distinción de lo dicho y lo dicho en lo no dicho; el silencio de sus líneas se nos presenta como un juego de huellas en la orientación del texto. Para acercarnos a esta problemática será necesario señalar primero algunas consideraciones previas al análisis de la novela Los sinsabores del verdadero policía de Roberto Bolaño para aclarar algunos casos particulares del fenómeno de la intertextualidad.

\section{Consideraciones previas}

Partiremos de dos rubros, uno desde la generalidad de la intertextualidad literaria y otro desde la particularidad de Roberto Bolaño en la novela que analizaremos. Respecto al primer aspecto podremos considerar los siguientes puntos para nuestra aproximación:

1) La co-presencia de textos no es uniforme: al existir una taxonomía de la intertextualidad, la co-presencia tendrá variaciones más allá de la cita explícita e implícita. Además de la alusión, tendremos el comentario de texto y la relación del hipertexto respecto a los géneros. Por ejemplo, no todos los hipertextos pertenecen al ámbito de la parodia ${ }^{3}$. Parte de nuestra

2 "Lo singular de esta novela, escrita a lo largo de tres lustros, es que incorpora material de otras obras suyas, desde 'Llamadas telefónicas' hasta 'Los detectives salvajes' y '2666', con la peculiaridad de que si bien a varios personajes los encontramos de nuevo- especialmente a Amalfitano, a su hija rosa y a Arcimboldilas variaciones son notables" (Masoliver: 7). La polémica es interesante en el sentido de proporcionarnos una prefiguración de otros proyectos de Roberto Bolaño; sin embargo, en este caso siempre entrará a discusión el proceso de compilación como reescritura de la recepción.

3 Obras como la Odisea de Homero, la Eneida de Virgilio y el Ulises de Joyce son un claro ejemplo de la relación entre un hipotexto y un hipertexto. 
inquietud, acerca de la intertextualidad en torno a los mundos posibles, viene de la siguiente observación por parte de Lubomir Doležel: "Pero esta concepción es lo suficientemente amplia como para ser teóricamente vacua y analíticamente inútil. Además, los intertextualistas absolutos ven sólo un lado de la moneda: la entrada de material existente en la formación de textos sucesores. No estudian lo que se hace con este material, cómo se modela, cómo se integra en la totalidad del nuevo texto" (Doležel: 279280). ¿Qué sucede entonces con la reescritura, la historia de la producción textual de un autor? ¿Entenderemos este fenómeno por sus correspondencias e imposturas o por el juego que abre la compilación en el ámbito de la recepción? Recordemos que este texto fue recogido a partir de papeles dispuestos por el autor.

2) El intertexto no sólo desplaza las lecturas, las transgrede: todo proceso de intertextualidad posee una relación con el ámbito de la percepción debido a la función que cumple en la orientación del texto ${ }^{4}$. Es decir, éste siempre nos invitará a una lectura por desplazamientos, a irnos hacia otros y regresar al mismo, pero siempre yendo más allá del texto en sí. En él, el intertexto no es el texto en sí. Siempre habrá un grado de transgresión. El intertexto es como la pieza de un puzzle que entra en más de un sitio y crea otra imagen dentro de él.

3) Pluralidad: los textos pueden ser tanto referencias literarias como no literarias, de varios autores y en contextos diversos, lo cual aumenta el carácter transgresivo en la intertextualidad, se convierten en un juego de apropiaciones en confrontación con la escritura. El orden de la significación "desafía toda pretensión de clausura" (Jitrik: 50).

4) Los límites taxonómicos se difuminan: en un espacio pequeño del texto se pueden encontrar varios tipos o la combinación de los mismos ${ }^{5}$. La pregunta sería ¿hasta dónde las definiciones siguen siendo sólidas frente a los nuevos textos que van surgiendo con el tiempo?

Así mismo, con base en lo anterior, tendremos que remitirnos a los siguientes puntos acerca del autor:

1) Un Bolaño lector: no es de extrañar el vínculo cercano que existe entre la lectura y la escritura, menos en el caso de la intertextualidad. Sin embargo,

4 Cfr. José Enrique Martínez Fernández en "La intertextualidad literaria" acerca de las observaciones de Riffaterre, p. 61. También el autor toma la perspectiva de Plett al considerar la etimología del término y da cuenta de su carácter unilateral: todo intertexto es un texto, no así en viceversa. Se trata de una relación entre ellos, a su vez de un juego de huellas en la orientación de los mismos si contextualizamos a este fenómeno en algún género literario, en nuestro caso, la novela. Sin embargo, queda claro que al ser una relación de textos existe un desplazamiento por parte del lector.

5 Pensemos en un ejemplo de la literatura latinoamericana contemporánea: El hombre que amaba a los perros, de Leonardo Padura. ¿Es un paratexto o un intertexto disfrazado de paratexto? ¿En qué sentido este título abre una lectura hipertextual respecto al relato de Raymond Chandler? Algo similar sucede en Los sinsabores del verdadero policía, pero en distintos grados y variaciones. 
la obra de este escritor posee una constante: es un lector voraz, pero podríamos considerarlo también como un e-lector en los términos que propone Luisa Block de Behar en Una retórica del silencio ${ }^{6}$ : "El lector es un autor en tanto ejerce esa apropiación activa de la que hablaba H. R. Jauss con respecto a la recepción de obras en las que cada renovación de 'horizontes de espera' renueva y modifica el valor y sentido" (Block de Behar: 79). Los personajes de Bolaño son una especie de lectores activos, el aspecto metaliterario en ellos transforma su horizonte 'personal'. La referencia a textos literarios será una constante en la obra de Roberto Bolaño.

2) Oscar Amalfitano profesor de literatura: la configuración del personaje también es un condicionante en la guía de la lectura, sobre todo en el caso de la poesía. Oscar Amalfitano además de ser profesor de literatura también conoce la filosofía.

3) Universo de Bolaño: la aparición de varios personajes y espacios repetidos en la obra de Bolaño es parte de un fenómeno llamado intratextualidad. José Enrique Martínez Fernández anota las siguientes aclaraciones en la evolución del término: "Se distinguiría la intertextualidad externa (relación de un texto con otro texto) de la interna (relación entre elementos del propio texto o de un texto consigo mismo) y la intertextualidad propiamente dicha (relación entre autores diferentes) de la intratextualidad (relación entre textos del mismo autor) [...]" (Martínez: 60). Este segundo fenómeno será importante en el conflicto que subyace por la presencia de personajes recurrentes en la obra de Bolaño.

4) Prólogo y Nota editorial: los paratextos que sirven como comentarios condicionan la lectura al señalar primero los antecedentes y frases del mismo escritor refiriéndose a esta novela. En el caso del segundo paratexto, éste funciona como un cinturón de legitimidad, pero esto no limita la condición de juego en las huellas del texto con relación a los grados de la intertextualidad.

\section{Amalfitano y "El corazón robado" de Arthur Rimbaud}

Oscar Amalfitano se encuentra en una nueva etapa de su vida al ser despedido de la Universidad de Barcelona y descubrir su homosexualidad en una edad avanzada ${ }^{7}$.

6 Tanto Oscar Amalfitano (personaje) y Roberto Bolaño son lectores que se apropian y cambian el valor de las lecturas, como veremos más adelante con algunos ejemplos. Ambos se adhieren a la tradición del lector como detective al estilo de Borges o Ricardo Piglia, por mencionar solamente dos casos identificables, en la literatura latinoamericana, bajo un mismo hilo temático.

7 Recordemos que Amalfitano comienza a buscar ejemplos de homosexualidad 'tardía' en la literatura mundial. Por ejemplo, con el autor de Muerte en Venecia se señala lo siguiente: "El único que se le venía a la cabeza era Thomas Mann y esa especie de mariposeo lánguido e inocente que sufrió en la vejez. Pero él no era tan viejo, pensaba, y además Thomas Mann probablemente por entonces ya chocheaba, lo que no era su caso" (Los sinsabores...: 137). 
Llega el momento en que la heterosexualidad, como el muro de Berlín (que da nombre al primer capítulo), se convierte en una ficción difícil de mantener, antes sedimentada y después en decadencia. Amalfitano recurre a algunos autores de la literatura para comprender su situación, pero ni Thomas Mann o ciertos casos españoles no le convencen por la vejez o lo bujarrones que llegaron a ser. Por ello recuerda un poema de Rimbaud (Le cœur volé) y hace, en voz del narrador, analogías retorcidas con él. No sólo lo recuerda, sino que lo recita en voz alta, "afición que tanto Amalfitano como Rosa habían heredado de Edith Lieberman" (Los sinsabores...: 138). Amalfitano recita el poema, la versión de 1912, Édition Berrichon $^{8}$. La novela ofrece pistas de la distorsión de este intertexto. Ocurre una apropiación del mismo para explicar su condición de homosexual y la ausencia de algo: "veía el fin de su heterosexualidad ahogada en la ausencia de algo que no podía precisar, una mujer, una heroína, una supermujer" (137). Además de insertar este poema en el fragmento número 21 , se comenta al final el texto por el valor que tuvo el poeta para escribirlo después de haber sido violado.

La co-presencia de textos no es uniforme porque a partir del poema citado puede observarse el carácter retrospectivo de las descripciones sobre la vida de Amalfitano. Esto sucede específicamente en el fragmento 21. Además de crearse una biografía imaginaria, la del caporal que violó a Rimbaud, se crea un paralelismo con el pasado institucional del personaje principal de la novela de Bolaño. Las analogías retorcidas, con base en la expansión del mundo ficcional que aporta el narrador, dan como resultado comprender el fin de su heterosexualidad debido a una ausencia que el personaje no puede precisar ${ }^{9}$. Sin embargo, desde la perspectiva de la trama obtenemos un paralelismo entre la violación de Rimbaud por parte del caporal y la violación "institucional" de Amalfitano por la Universidad de Barcelona. Dos elementos de autoridad se encuentran entre sí como parte de ese asalto a la identidad, a la transgresión del individuo: el que padece Rimbaud rumbo a la comuna y el de Amalfitano que apenas descubría un nuevo mundo fuera del muro. Después de recitar el poema viene el siguiente pensamiento desde la perspectiva del personaje:

Todo estaba claro, pensaba Amalfitano entonces, el poeta adolescente degradado por la soldadesca justo cuando se dirigía, ¡a pie!, al encuentro con la Quimera, y qué fuerte era Rimbaud, pensaba Amalfitano renunciando ya a cualquier consuelo, emocionado y admirado a partes iguales, para escribir casi inmediatamente después el poema, con el pulso firme, las rimas originales, las imágenes que oscilaban entre lo cómico y monstruoso... (Los sinsabores...: 138139)

8 Puede tomarse como punto comparación la versión de 1895 de la edición Vanier, misma que utiliza Javier del Prado en su edición bilingüe de las obras completas de Rimbaud donde se cambia "Au gouvernail on voit des fresques" por "A la vespréeils Font des fresques" (Rimbaud: 331).

9 Javier del Prado, en una nota sobre el título del poema, confiesa las razones de por qué ese título y no otro de los dos también conocidos: “[...] hemos optado por este último que, al concluir el poema, en el último verso, le da, a nuestro entender, su sentido 'profundo: a partir de ahora ya no puede existir el espacio del corazóndel amor, del sentimiento" (331). Tal vez en Amalfitano no es que ya no haya espacio para el corazón, pero coincide esta lectura con la ausencia de algo que ya no tiene espacio en él. 
Amalfitano se apropia del texto, pero a su vez crea una distancia con él, y termina funcionando como pulsión de alteridades. En el encuentro en busca de la Quimera, ambos son degradados y se percibe esa ausencia-difícil de precisarpor medio de la presencia de la escritura: Rimbaud mediante el poema y Amalfitano en la intimidad de las cartas con Padilla. No se trata solamente de un proceso de des-contextualización y re-contextualización, más bien se crea un nuevo mundo a partir de otros ${ }^{10}$. El narrador accede a esta información por la perspectiva del personaje, pero es el punto de vista afectivo el que construye un puente con el poema de Rimbaud. Dicho puente se determina por la inaccesibilidad ${ }^{11}$ de Amalfitano a sí mismo: el texto lo desdobla en un ente que oscila, como las imágenes de Rimbaud, entre lo cómico y lo monstruoso.

En relación con el intertexto Le cour volé, podemos añadir también la perspectiva del narrador a diferencia de la de Amalfitano. Los desplazamientos siguen ocurriendo, pero ahora el texto es transgredido de otra forma; primero mediante las analogías retorcidas de Amalfitano y después por el silencio del caporal que se descubre mediante el recurso de las biografías imaginarias (mínimas): "Lo que Amalfitano jamás sabría es que el caporal de «moncourcouvert de caporal», el hijo de puta que abusó de Rimbaud, había sido soldado del Ejército de Bazaine en la aventura mexicana de Maximiliano y Napoleón III" (Los sinsabores...: 140). El salto del texto principal, además de las posibles referencias históricas todavía no $\operatorname{precisadas~}^{12}$, no es hacia otros textos más que a sí mismo respecto a la orientación de la trama en un espacio y tiempo histórico: el imperio de Maximiliano a través de una breve historia sobre el soldado que, en el universo de Bolaño, violó al joven Rimbaud.

El recurso no sólo nos recuerda a Marcel Schwob en Vidas imaginarias, sino a toda una tradición en Latinoamérica acerca de las biografías imaginarias, en especial a aquellas que se refieren a la infamia aunque su intencionalidad sea otra a la que propone Roberto Bolaño. El caso más paralelo que encontramos es el de Historia universal de la infamia de Jorge Luis Borges con La literatura nazi en América de Roberto Bolaño. Sin embargo, es necesario agregar la siguiente observación de Celina Manzoni:

Las 'biografías infames' que construye o eventualmente reescribe Borges responden, a su vez, a una tradición que él remite a 'relecturas de Stevenson y Chesterson y aún de los primeros films de Sternberg y tal vez a cierta biografía de Evaristo Carriego'. Por mi parte, las vinculo además con una tradición de literatura argentina que se remonta a Sarmiento, quien con el Facundo inaugura la serie de lo que denomina ‘biografías inmorales', que con la del Fraile Aldao y

10 Cfr. Martínez Fernández (94).

11 A este aspecto sobre la alteridad en la escritura (particularmente en la ficción), podemos agregar la observación de Wolfgang Iser en "La ficcionalización: dimensión antropológica de las ficciones literarias" en el libro Teorías de la ficción literaria, comp. Antonio Garrido Domínguez (53). En dicho apartado, Iser deja en claro cómo las ficciones literarias llegan a una realidad inaccesible para la vida cotidiana mediante una estructura de doble significado. El juego metaliterario de esta novela de Bolaño consiste en esta estructura de doble significado por medio de un puente: el poema de Rimbaud.

12 Javier del Prado, en otra nota de su edición crítica de las poesías completas de Arthur Rimbaud, dice lo siguiente acerca de lo que pudo haber sido lo que produjo este poema: "Existen, en efecto, suficientes dudas en relación a este acontecimiento" (23). 
la de Chacho Peñaloza se constituyen en textos fundacionales y en el momento al que se contraponen las 'biografías infames' de Borges, no sólo la divergente intencional, sino también la extensión ${ }^{13}(25)$.

En el caso de Bolaño estas biografías se extienden al ámbito de la lectura, a la educación sentimental del personaje. La transgresión del poema de Rimbaud al ser recitado por Amalfitano ocurre en el plano del tiempo ${ }^{14}$ : se pasa de uno psicológico en el profesor de literatura de Santa Teresa a otro cuasi-histórico, al exceso de una violación que se incrusta en el caos de un muro derribado en Amalfitano. Ambos tiempos son unidos por Rimbaud como texto, uno que comenta al otro a través del narrador, cuya información complementa a la del personaje. La perspectiva del lector es la que converge a ambas, pero es el texto de Bolaño el que vuelve al poema su contemporáneo.

\section{Lugones, Kafka y los monos según Amalfitano}

Uno de los fragmentos más ricos de Los sinsabores... por las conexiones de su propio palimpsesto es el número 24. Oscar Amalfitano se entera de la desaparición de su hija, pero no de la manera en la que podría pensarse: sola o en compañía de algún conocido de Santa Teresa. En realidad, ella va acompañada de un negro: "Cuando Amalfitano supo que su hija había desaparecido en compañía de un negro, sin que viniera a cuento recordó una frase de Lugones que leyera muchos años, pero muchos años atrás" (Los sinsabores....: 144). Tenemos hasta aquí dos manifestaciones textuales, una completamente marcada en forma de alusión y la otra sin marcar, ambigua y solamente perceptible si se conoce una obra anterior de Roberto Bolaño. El negro, al menos por la sola característica de su color de piel, resulta ser una coincidencia textual: Oscar Fate de 2666 (con quien Amalfitano sí tiene contacto en esa novela). Entramos en el terreno de la intratextualidad. Se trata de un personaje, un periodista norteamericano. En el caso de Los sinsabores... no hay más desarrollo, aunque más adelante plantearemos algunas imposturas, más bien observaciones sobre las diferencias entre ambos mundos.

En un segundo término, continuando con la alusión de Amalfitano a Leopoldo Lugones, está la cita sobre el cuento "Izur", parte del libro Las fuerzas extrañas. Amalfitano recuerda lo siguiente acerca de los negros: "Las palabras de Lugones eran las siguientes: "es sabido que la juventud constituye la época más intelectual del mono, parecido en esto al negro” ¡Qué bestia, el Lugones! Y después recordó el

13 Celina Manzoni en otro texto retoma la biografía mínima, sobre todo el sentido de Marcel Schwob al crear un caos con rasgos humanos. Manzoni también establece una relación con Historia de la infamia de Jorge Luis Borges, incluso la cataloga como 'íntima'. Mientras Manzoni destaca el caos como parte de una parodia del canon occidental, bien puede encontrarse una lectura similar con respecto al poema de Rimbaud, pero desde la recepción de un lector latinoamericano. Véase "Biografía de artista y contemporaneidad en Roberto Bolaño", concretamente las páginas 33-34.

14 Ricoeur resalta esta repetición como una expresión emblemática por mantener juntos al tiempo mundano, público y mortal de manera improbable, véase p. 835 Tiempo y narración III. La forma en que se perciben estos tiempos es por la intencionalidad del narrador, distinta de la de Amalfitano debido a que ignora ese hecho ficcional y la repetición de un fragmento del poema (el caporal). La historia del soldado distiende el fragmento que le precede, es una forma de restirar el tiempo por medio de la biografía mínima. Un supuesto tiempo histórico es unido junto al tiempo psicológico de Amalfitano desde otra perspectiva. 
cuento, el argumento del cuento de Lugones..." (Los sinsabores...: 144). La dirección de estas palabras posee una jerarquía. A partir de la desaparición de su hija (Rosa) con un negro, Amalfitano recuerda una cita y de la cita pasa al argumento: un hombre que intenta hacer hablar a un mono hasta que éste muriendo de sed logra pedirle agua al amo. Más adelante en el texto de Bolaño ocurre otra deformación por parte del personaje cuando se cita el final del cuento:

(Amalfitano lo imaginó por un segundo descerrajándose un tiro en la boca en el rincón más oscuro y fresco de su biblioteca, tragando veneno en una buhardilla llena de telarañas, colgándose desnudo de la viga más alta del cuarto de baño, ¿pero era posible que el cuarto de baño tuviera vigas?, ¿en dónde lo había leído o visto? Amalfitano no lo sabía). (144-145)

El impacto del recuerdo de este argumento, el mono casi humanizado por la agonía, revienta en el suicidio de Leopoldo Lugones. Un salto de lo literario a lo histórico. De la agonía del mono al que se le enseña a hablar mientras pide agua su amo, pasamos al suicidio del escritor como otra clase de agonía. Ambos tienen en común quizá la sed, pero en distintas versiones: una por el agua y falta de alimento, la otra por amor y falta de correspondencia ${ }^{15}$.

Tenemos hasta este momento una relación a partir de la intratextualidad en dirección a una cita, después a un argumento y luego hacia un hecho histórico. Los grados de intertextualidad son distintos en un solo fragmento, van del comentario a la cita, después al hipertexto en forma de alusión y apropiación. Pero existe otro momento en particular donde los límites taxonómicos salen a relucir en tan poco espacio al aludir a otro texto, concretamente a Informe para una academia de Franz Kafka:

Qué ópticas tan distintas, pensaba Amalfitano, el querido Kafka se ponía, sin más, en el pellejo del mono; Lugones pretendía hacerlo hablar, Kafka lo hacía hablar. El cuento de Lugones, que consideraba extraordinario, era un cuento de terror. El de Kafka, el texto incomprensible de Kafka, volaba también por los dominios del terror pero asimismo era un texto religioso, lleno de humor negro, humano y melodramático, duro e insignificante como todo aquello que es duro de verdad, es decir como todo aquello que es blando. Amalfitano se puso a llorar. (Los sinsabores...: 145)

En un breve espacio dentro del párrafo podemos enumerar algunas manifestaciones: 1) las alusiones son marcadas primero por el apellido del autor; 2) la alusión es completamente marcada en cuanto a la referencia del cuento, se nos da su argumento, no así el título; y 3) este fragmento cumple también una función metatextual, se trata de un texto que está haciendo pequeñas comparaciones entre uno y el otro a partir de la semejanza de un mono como eje central de su historia aunque en distinta forma ${ }^{16}$. Al final, por supuesto, encontramos la distorsión a

15 Léase "Cuando Lugones conoció el amor" de Maria Inés Cárdenas de Monner Sans, Seix Barral, Buenos Aires, 1999. Se maneja otra tesis distinta a la del suicidio por decepción ideológica.

16 A esta observación, por la creación de una imagen, podemos remitirnos al ensayo de Jorge Luis Borges Kafka y sus predecesores. Bolaño nos crea una visión de sus predecesores y puede condicionar la lectura a partir de 
través de la apropiación del personaje: Amalfitano llora y encuentra en su realidad cotidiana en Santa Teresa pequeños enigmas que tienen sus respuestas tatuadas en la frente. Es ahí, en ese fragmento, cuando el personaje abre las cortinas.

\section{La poesía moderna latinoamericana y el Tao Te King de Santa Teresa}

Existen dos apartados que repiten algunos de los patrones anteriores, pero éstos están orientados por la historia de la literatura y los paralelismos en Los sinsabores....El primero de ellos es acerca de las clases impartidas por Oscar Amalfitano, particularmente en la delimitación de la poesía moderna en Latinoamérica ${ }^{17}$. En una de sus clases menciona dos títulos de poemas que tienen algo de especial. Uno de ellos es de Nicanor Parra y el otro de Ernesto Cardenal, con ambos, dice Amalfitano, comienza la poesía moderna latinoamericana:

Ambos textos, «El soliloquio» y el «Viaje», son las dos caras de la poesía moderna, el demonio y el ángel, respectivamente (y no olvidemos como dato curioso, pero tal vez un poco más de eso, que en el «Viaje» Ernesto Cardenal menciona a Nicanor Parra), acaso el momento más lúcido y terrible a partir del cual el cielo se oscurece y comienza la tormenta. (130)

Los textos a los que se refiere son "El soliloquio del individuo" y "Viaje a Nueva York" de Nicanor Parra y Ernesto Cardenal, respectivamente. Ambos van acompañados, en el comentario de Amalfitano, por su fecha y lugar de publicación, el primero en 1954 y el segundo en 1974.

Las fechas pueden aturdir a algunos lectores debido a su cercanía con el mundo contemporáneo. La siguiente pregunta que pudiera formularse un lector sería: ¿la poesía moderna en Latinoamérica empieza con esos dos poemas teniendo los antecedentes que se tienen? El fragmento, además de ser peculiar en el estilo de Bolaño $^{18}$, es lo que podríamos llamar un hueco intertextual. En otras palabras, un hueco intertextual puede entenderse como una huella que nos exige ir a otros textos y convertirnos en detective de la poesía moderna latinoamericana. En primer lugar, los títulos son paratextos que nos remiten al contenido de los poemas, a los versos de Nicanor Parra y los de Ernesto Cardenal. En segundo lugar, da pie a pensar en lo que se entiende como poesía latinoamericana moderna y a buscar sus ejemplos, la subordinación de los paratextos funciona a partir de esa especie de

esta comparación. Además, podemos agregar las observaciones de Dölezel cuando critica la influencia como algo unidireccional mientras que la intertextualidad "[...] es bidireccional; resulta de textos que comparten rastros semánticos sin tener en cuenta su orden cronológico. Los textos están conectados unos con otros, gracias a la intertextualidad, por medio de una relación de mutua iluminación semántica" (Dölezel: 281).

17 Hay otro momento de las clases de Amalfitano donde es más notoria una orientación lúdica de la escritura. El apartado se encuentra en la página 131 cuando juega con las cualidades o personalidades y las conjuga con nombres de escritores. También sucede cuando lanza preguntas a los alumnos sobre a quién alojarían en su casa y por qué. Se trata de uno de los momentos más lúdicos con el uso de los nombres de los autores dejando un hueco para la interpretación de sus vidas.

18 Pensemos en comentarios 'atrevidos' como los de uno de los hermanos Schiaffino en La literatura nazi en América, en defensa de la violencia de las barras bravas. 
hueco histórico. Si este fenómeno literario comienza con esos dos poemas, ¿cuáles le siguen? El fragmento es una provocación al diálogo.

Respecto a lo anterior, podemos permitirnos un breve ejercicio con ayuda de un texto moderno para dialogar con la postura de Amalfitano y demostrar las diversas variaciones que pueden surgir de este fenómeno. Como se trata de un hueco intertextual, el experimento puede dar algunos resultados interesantes en el proceso de lectura y la manifestación de nuevos mundos posibles. No sólo nos llega la pregunta acerca de dónde comienza la poesía latinoamericana moderna, sino el porqué de las imágenes del ángel y el demonio. Este elemento se usa como el manejo de las dos caras de la moneda de este fenómeno, principalmente cuando el suelo se oscurece para dar paso a la tormenta. Pero si revisamos a Rilke en Elegías de Duino, encontramos que todo ángel es terrible: "Pues lo bello no es/ sino el comienzo de lo terrible, lo que todavía soportamos, / y si tanto lo admiramos es porque su serenidad desdeña/ destrozarnos. Todo ángel es terrible" (Rilke: 27). Entonces, ¿cuál de los dos poemas es el ángel y quién el demonio?, ¿por qué no los dos al mismo tiempo? Las imágenes y conclusiones pueden ser muchas, desde una lectura histórica de estos poemas hasta refutaciones por medio de la historia de la poesía latinoamericana o por medio de la misma poesía moderna. A final de cuentas, este hueco intertextual es también un espacio para la creación de sus predecesores. No se leerá igual a Parra y Cardenal, en especial estos poemas, después de la aseveración de Amalfitano en su clase de literatura.

Por otro lado, el juego de los paralelismos puede ser todavía más cercano al anterior ejemplo donde el poema de Rimbaud posee una orientación con base en los sucesos de la vida de Oscar Amalfitano. Es decir, en ese caso tenemos que tener el antecedente del despido para la configuración del personaje con base en el poema. En el caso del paseo de Amalfitano el paralelismo es simultáneo. Mientras en el primero hay una dilación de los hechos, en el caso del Tao Te King es casi simultáneo a lo que ocurre en la narración, pero a su vez desprende una alteridad. Amalfitano comienza a pensar en la frase del libro de Lao Tse, teniendo en mente también su relación con Padilla: “ «Su identidad es el misterio./Y en este misterio/ se halla la puerta de toda maravilla.» ¿Cuál era la identidad de Padilla?, pensó alejándose del puesto ambulante en dirección a un gran letrero luminoso en la mitad de la calle Mina." (Los sinsabores...: 113). Más tarde se encuentra a un niño que lo lleva por un camino desconocido cerca de dos carros destartalados y Amalfitano supone lo que le ofrece y lo rechaza. Al final, recuerda la frase del Tao Te King: "Se le llenaron su ojos de lágrimas. Su camino es el misterio" (114). Encontramos un diálogo a la par entre el camino que sigue Amalfitano de la mano del niño y el de la virtud. Recordemos que Tao Te King es el libro del camino de la virtud. ¿Cuál es el misterio que une a Padilla y el niño entre los dos carros destartalados?: "El misterio, la maravilla de ser joven y no tener miedo y luego de pronto tenerlo" (113). El paralelo es doble: el camino del texto oriental en el camino de las calles de Santa Teresa y la juventud de Padilla a lado de la del niño. Amalfitano es un viejo que apenas se ha descubierto como homosexual. 


\section{Architextualidad y reescritura: el intercambio de géneros}

Otro de los planteamientos que podemos desarrollar, no sólo en los límites taxonómicos de la intertextualidad, sino también en los géneros literarios, ocurre dentro del fenómeno architextual. Ciertos rasgos nos dirán si un texto pertenece a algún género o si posee otros que lo muestren como algo inclasificable. En el caso de Los sinsabores... encontramos un juego de reescritura a partir del eco de obras anteriores (en cuanto a fecha de publicación). En 1997, Roberto Bolaño publica en el sello editorial de Anagrama su libro de cuentos Llamadas telefónicas. Entre los textos que se encuentran en él, está uno titulado "Otro cuento ruso". El relato trata de la historia de cómo un hombre llamado Amalfitano cuenta a un compañero suyo, luego de discutir sobre una cualidad del arte, una historia que le habían contado antes: la historia de un sorche sevillano que al ser capturado por los rusos es torturado ya que nadie entiende lo que dice hasta que al pronunciar la palabra 'coño' las pinzas de tortura provocan que salga la palabra 'Kunst' (arte). Sus verdugos lo dejan libre al pensar que es un artista. El cuento inicia de la siguiente manera: "En cierta ocasión, después de discutir con un amigo acerca de la identidad peregrina del arte, Amalfitano le refirió una historia que a él le contaron en Barcelona" (Llamadas telefónicas: 101). Se trata de un cuento en el que podemos ver cómo Amalfitano le cuenta a alguien indeterminado (un amigo) la historia que le contaron sobre el sorche sevillano en la Segunda Guerra Mundial.

En Los sinsabores... ocurre algo en el fragmento número 7. Se cuenta la misma historia, desde un narrador en una posición similar que el de "Otro cuento ruso", por medio del conocimiento de Oscar Amalfitano. Las diferencias son sutiles, muchas de ellas nada sustanciales respecto al argumento de la aventura del sorche sevillano. Existe una que otra palabra agregada, pequeños cambios de puntuación, pero a final de cuentas se trata de un cuento dentro de la novela. Entramos en un problema de architextualidad. ¿Qué hace diferente sustancialmente, en cuanto a género, a "Otro cuento ruso" del fragmento número siete para considerar a este último parte de la novela sin desentonar al mundo propuesto? La respuesta quizá podemos encontrarla al comparar las primeras líneas de ambos. La de Los sinsabores... dice: "En cierta ocasión, después de discutir con Castillo sobre la identidad peregrina del arte, Amalfitano le refirió una historia que a él le habían contado en Barcelona". (Los sinsabores...: 93). La única diferencia visible entre las primeras líneas de ambos textos es uno de los personajes presentes en la conversación. Mientras en el cuento aparece "un amigo", en la novela aparece Castillo, el falsificador de pinturas de Larry Rivers, una nueva amistad de Amalfitano en Santa Teresa. La brecha de los géneros ocurre por el cambio de una sola palabra. Mientras en el primero se trata de un sujeto indeterminado, en la novela vemos a un personaje parte de ese mundo posible llamado Los sinsabores del verdadero policía. La configuración, de acuerdo con la lógica de su texto, es lo que la hace permanecer en un plano más abierto al del cuento.

Doležel en Heterocósmica no desarrolla el tema de la reescritura, su lectura se basa solamente en una de tipo posmoderna a partir de su relación con mitos o textos antiguos. Sin embargo, en uno de los tipos de reescrituras posmodernas hay una que puede ser útil para entender lo que ocurre con Roberto Bolaño. El segundo tipo se indica lo siguiente: "La expansión extiende el campo del protomundo al 
rellenar sus huecos, construir una prehistoria o una poshistoria, etc. El protomundo y el mundo sucesor son complementarios. El protomundo es colocado en un nuevo contexto y se cambia así la estructura establecida" (288). Ninguno de los tres tipos explica en su totalidad lo que ocurre, más bien sucede en forma de matices, pero el segundo tipo atina en el rasgo de expansión. En la novela Los sinsabores... se expande a diferencia del cuento aislado en su propio mundo. El problema a plantear es el siguiente: ¿cuál de los dos es el protomundo? ¿Cuál de los dos es el texto-espejo del otro?

Quizás en este apartado sea necesario agregar alguna postura que nos haga distinguir del comportamiento de un género entre el otro, sobre todo a partir de tipología que actualicen la problemática de los géneros. En la tercera parte de Los géneros literarios: sistema e historia, libro escrito por Antonio García Berrio y Javier Huerta Calvo, se retoma una característica del cuento en contraposición al comportamiento de la novela. En el libro se cita la siguiente aseveración de Edelweiss Serra:

El cuento no crea como la novela un cosmos o mundo completo, sino ofrece un núcleo acabado de vida; puede ser una experiencia límite, un acontecer extraordinario... siempre una singladura presentada in medias res. Mientras la novela es un proceso acumulativo infinito, el cuento se arroga un principio interrogativo finito. El cuento, en tanto mensaje literario, es un acto de expresión y comunicación. Este acontecer idiomático significativo pone en juego los máximos recursos de la lengua tanto en función del contenido que comunica cuanto en la función expresiva de lo comunicado, de donde ambos planos se identifican o simbolizan. (cit. en Berrio y Huerta: 178)

Mientras que "Otro cuento ruso" se comporta como un núcleo acabado en Llamadas telefónicas, el fragmento número siete se integra a un cosmos, pues es parte de ese proceso acumulativo infinito de Los sinsabores.... En pocas palabras, podemos notar los límites taxonómicos de los géneros a partir de la expansión de uno de ellos.

\section{Algunas imposturas intratextuales: observaciones finales}

Hasta ahora hemos comprobado la dirección bilateral de la intertextualidad, no sólo entre un autor y otro, sino en la extensión de un mundo posible a partir de otro. Nuestro fin en este trabajo consistió en plantear varias observaciones teóricas a partir de un texto conflictivo como Los sinsabores.... A partir de cada uno de los apartados anteriores, es posible planear otro trabajo en específico para encontrar más variantes o resolver las incógnitas que nos han surgido en el desarrollo de esta escritura. Sin embargo, una de las discrepancias que tenemos en la relación de los mundos posibles con la intertextualidad, se debe a la siguiente aseveración de Lubomir Doležel: "La intertextualidad explícita, la cita en concreto, es de un interés menor para el estudio literario; el verdadero desafío es la intertextualidad implícita, los rastros semánticos de textos ocultos" (281). El teórico parte de observaciones previas en torno a lo implícito, los huecos y la saturación, pero 
descartar en tan pocas líneas el valor de la cita textual es perder la percepción de los mundos posibles.

El mismo texto explícito es una posibilidad de mundo que entra en otro, hay una apropiación de uno por parte de otro, tal vez contrario a lo que expresa, pero que la ficción hace de tal manera posible para que coexistan en un mismo espacio. El ejemplo que tomamos fue el de Rimbaud, un texto que Amalfitano recita de memoria. Darle menor interés a la cita es despreciar el contexto en el que se sitúa. Recordemos una de nuestras consideraciones previas: el texto insertado no es el texto en sí. También hay que recordar que la misma cita guarda algo implícito en ella. Si la intertextualidad orienta la lectura, también orienta el mundo en el que se desarrolla.

Por otro lado, la intratextualidad en Los sinsabores... tiene gran importancia debido a la aparición de otros personajes de obra como Los detectives salvajes, Llamadas telefónicas, Estrella distante, Putas asesinas ${ }^{19}$ y 2666. Sobre todo es necesario apuntar algunas interrogantes respecto a esta última novela y la más grande de Roberto Bolaño o su obra mayor en palabras de la misma editorial ${ }^{20}$, curiosamente 2666 y la que hemos analizado a lo largo de este artículo son póstumas. El lector de ambas obras podrá notar las diferencias entre la vida de los dos Amalfitanos desde sus esposas, la fijación con la poesía y la aparición de la filosofía en otro, los turnos en que Rosa y él salen de la casa, quien lo vigila, entre otras variaciones. Es importante hacer estas anotaciones para entender el universo de Roberto Bolaño y cómo se conectan las diferentes obras entre sí, ya sea de manera congruente o bien por los problemas que podemos plantearlos rumbo a nuevas perspectivas de los mundos ficcionales.

El primer ejemplo congruente entre una novela y la otra, es el de Amalfitano cuando se siente vigilado en casa de Santa Teresa. En 2666, leemos lo siguiente: "Cuando volvía a la casa, no por la puerta trasera, sino por la delantera, asomaba el cuello por encima de la verja y miraba la calle en ambas direcciones. Algunas noches tenía la impresión de que lo espiaban" (2666: 254). A continuación, veremos cómo se da un momento similar en Los sinsabores...: "Poco después comenzó a sentirse vigilado. En otras épocas de su vida ya había experimentado esta sensación: la de la presa en el bosque que husmea al cazador" (Los sinsabores...: 69). Encontramos coincidencias en palabras como "impresión", "espiar", "sentirse", "vigilado". Ambos mundos comparten la vigilancia al personaje de Oscar Amalfitano, alguien en un coche enfrente de su casa y él percibiéndole a pesar de no verlo (al menos en esos momentos) todavía.

Sin embargo, en el caso de las esposas y la actitud de Amalfitano frente a ellas varia demasiado, al punto de existir impostura si queremos forzar el universo como un UNO donde todo es congruencia de universos. En ese sentido, el universo de Roberto Bolaño es parecido al de los mitos antiguos donde cada personaje tiene versiones diferentes de sus padecimientos o aventuras. En 2666, su nombre es Lola mientras que en Los sinsabores... su nombre es Edith Lieberman. La primera más

19 Recomendamos en este apartado el trabajo de Erica Cecchinato "Los sinsabores del verdadero policía: la intertextualidad salvaje de Roberto Bolaño" para una descripción detallada de la figura de Pedro Monge (Monje). Véase Revista Orillas, Nº. 3, año 2014.

20 En la solapa del libro Los sinsabores del verdadero policía puede leerse lo siguiente: "Su novela póstuma 2666, está considerada unánimemente su obra mayor”. 
cercana a la locura que la segunda. Lola abandona a Amalfitano y a Rosa para poder visitar a un poeta que conoce en el manicomio, contrae SIDA y tiene un hijo en Francia mientras que con Edith Lieberman nunca se menciona un escape, solamente que enferma y es atendida en Brasil hasta que muere. De ella se dice lo siguiente en Los sinsabores...: "descalza en la arena, como si supiera cosas que él jamás iba a saber y que ella nunca le diría" (259). En 2666 la aparición de la correspondencia, en lugar de ser cumplida por Padilla, ocurre con Lola quien cuenta muchas cosas de las que hace en su viaje con el poeta en el manicomio. El manejo de información y la actitud ante ella (recordemos que Edith Lieberman es incluso más hermosa que las playas de Brasil) es distinto y se dicen cosas que la otra no dice o bien que en el mundo de Los sinsabores...no se nos proporciona. Las diferencias son claras en los textos al compararlos ${ }^{21}$.

$\mathrm{Si}$ retomamos el prólogo de Masoliver a partir del ejercicio anterior, encontramos que su postura al defender esta novela como una obra que no está incompleta, puede ser que esté correcto en el ámbito estético, pero no así en el de las fronteras de la ficción. Recordemos la siguiente observación de Thomas Pavel: "Los mundos reales se presentan, sin ninguna duda, como tales, completos y consistentes, mientras que los mundos ficticios son intrínsecamente incompletos e inconsistentes" (Pavel: 171). Como no podemos asegurar cuántos hijos tenía Lady Macbeth, de igual manera no podemos asegurar si Amalfitano tenía dos esposas o si Lola y Edith Lieberman son las mismas, si las entradas y salidas de Rosa eran otros días y por eso a veces salía antes o después que su padre. El mundo de Los sinsabores... es incompleto e inconsistente como el de cualquier otro mundo ficcional. Prueba de ello, las diferencias con 2666.

En conclusión, ambas novelas son propuestas de mundos distintas a pesar de pertenecer a un mismo universo. La intencionalidad en cada una de ellas es lo que las aleja si queremos considerarlas iguales bajo una misma lógica y congruencias. Pero sobre todo debemos tomar en cuenta para futuros estudios los cambios de perspectivas y puntos de vista en específico en cada texto, la filiación y selección de información narrativa es una clave en el fenómeno intertextual de estas obras.

En el plano de la intratextualidad, las imposturas son inconsumerables, no pueden ser compatibles en su totalidad, pero coexisten al pertenecer a un universo que les permite con armonía la existencia de esposas distintas para Amalfitano con características muy similares. Ponerlas como un solo mundo las vuelve excluyentes y sería parte de una intencionalidad externa a la de cada texto. Esto ya sería trabajo de una reescritura fuera de la de Roberto Bolaño.

A pesar de tratarse de un Oscar Amalfitano en ambas, ellos no son el mismo Oscar Amalfitano, cada uno, aunque parecidos, es una proyección única bajo la lógica de su mundo. Uno más cercano a la locura (2666 con las voces que le dicen que es un maricón y el libro colgado del tendedero) y el segundo más cercano al descubrimiento de la homosexualidad, a la caída de su muro de Berlín. La intertextualidad debe entenderse no sólo como orientación de una lectura, sino como la orientación de distintos mundos con un contexto distinto. Al no entender que cada una es singular y enmarcarlas completamente entre sí, presenta

21 Así también cuando Amalfitano es vigilado, los narradores de ambas novelas desvarían en el orden de salida de la casa. En Los sinsabores...Amalfitano siempre sale antes que su hija a la calle (272), mientras que en 2666 sucede al revés (254). 
incongruencias que fragilidad o las hacen imposibles. Por ello hay que considerarlas como dos propuestas de mundo en un mismo universo que los conectan los temas y su tratamiento. Cada texto tiene su propio juego de huellas en la orientación de sí.

\section{Referencias bibliográficas}

Bolaño, Roberto, "Otro cuento ruso", en Llamadas telefónicas. Barcelona: Anagrama, 2006.

-2666. Barcelona: Anagrama, 2007.

- Los sinsabores del verdadero policía. Pról. de J. A. Masoliver Ródenas. Barcelona: Anagrama, 2011.

Doležel, Lubomir. Heterocósmica: ficción y mundos posibles. Trad. Félix Rodríguez. Madrid: Arco, 1999.

García Berrio, Antonio y Javier Huerta Calvo. Los géneros literarios: sistema e historia. Madrid: Ediciones Cátedra, 1995.

Jitrik, Noé. Los grados de la escritura. Argentina: Ediciones Manantial, 2000.

Manzoni, Celina, "Biografías mínimas/ínfimas y el equívoco del mal", en Celina Manzoni (ed., comp. y pról.). Roberto Bolaño: la escritura como tauromaquia. Buenos Aires: Ediciones Corregidor, 2002.

- "Biografía de artista y contemporaneidad en Roberto Bolaño", en Celina Manzoni (ed., comp. y pról.). Violencia y silencio. Literatura latinoamericana contemporánea. Buenos Aires: Ediciones Corregidor, 2005.

Martínez Fernández, José Enrique. La intertextualidad literaria. Madrid: Ediciones Cátedra, 2001.

Rilke, Rainer María. Elegías de Duino. Trad. Lorenza Fernández del Valle y Juan Varvejal. México: UNAM, 2004.

Rimbaud, Arthur. Poesías completas. Ed. bilingüe de Javier del Padro. Madrid: Ediciones Cátedra, 1998.

Pavel, Thomas, "Las fronteras de la ficción", en Antonio Garrido Domínguez (comp.). Teorías de la ficción literaria.. Madrid, 1997. 